\title{
Awareness and Opinion regarding Syndromic approach towards STI/RTI management among private practioners in Patiala, north India
}

\author{
Singh S. ${ }^{*}$, Rajinder S. B. ${ }^{2}$ \\ DOI: https://doi.org/10.17511/ijphr.2016.i2.06
}

1* Sumeet Singh, Senior Resident, Department of Community Medicine, Government Medical College, Patiala, Punjab, India.

2 Balgir Rajinder S., Associate Professor, Department of Community Medicine, Govt. Medical College, Patiala, Punjab, India.

Introduction: Sexually Transmitted Infections (STIs) and Reproductive Tract Infections (RTIs) have been a major public health problem in all the developing countries. STDs and their complications are amongst the top five disease categories for which adults seek health care. The health-seeking behaviour among the general population in India shows that for STI/RTI treatment people prefer non-modern medicine private practitioners. Aims and objectives: 1) To determine awareness and opinion regarding syndromic approach towards STI / RTI case management among the practitioners in private sector. 2) To compare the results with the previous large scale studies and to provide suitable recommendations. Material and methods: This cross sectional study was carried out in urban Patiala in 2012-13 among 100 randomly selected private practioners by personal visiting and getting responses to a set questionnaire. Group A constitutes allopathic and group B constitutes non allopathic practioners. Results and observations: $60 \%$ in Group A and 38\% in Group B admit to be aware of syndromic approach but only 16 in Group A and 4 in Group B had correctly replied about no. of kits available in syndromic approach. $70 \%$ in both the groups were of the opinion that it will generate better follow up while $35-40 \%$ believe there is a risk of over treatment with this approach. Discussion: Since, practice of syndromic case management of STIs is presumed to be dependent on the practioners individual opinion and attitude hence it is beneficial to know about their opinion. To raise the rates of treatment as per WHO advised strategy of Syndromic management, confidence building and appropriate knowledge to the health care providers is a must. Conclusion: Apparent need is there for regular educational activities for licensed private practioners as short trainings, $\mathrm{CME}$, seminars on standard treatment protocols.

Keywords: Sexually transmitted infections, STI/ RTI, Syndromic management, Health care providers, Reproductive health

Corresponding Author

Sumeet Singh, Senior Resident, Department of Community Medicine, Government Medical College, Patiala, Punjab, India.

Email: 85.sumeet@gmail.com
How to Cite this Article

Singh S, Rajinder SB. Awareness and Opinion regarding Syndromic approach towards STI/RTI management among private practioners in Patiala, north India. Public Health Rev Int J Public Health Res. $2016 ; 3(2): 75-81$.

Available From

https://publichealth.medresearch.in/index.php/ijphr/ article/view/35
To Browse

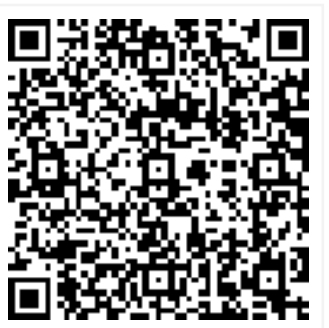

Manuscript Received 2016-03-25

Conflict of Interest No
Review Round 1 2016-04-07

Funding

$\mathrm{Nil}$

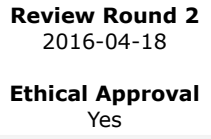

Ethical Approval Yes

Review Round 3

Plagiarism $\mathbf{X}$-checker $8 \%$
Accepted 2016-04-30

(C) 2016 by Sumeet Singh, Balgir Rajinder S. and Published by Siddharth Health Research and Social Welfare Society. This is an Open Access article licensed under a Creative Commons Attribution 4.0 International License https://creativecommons.org/licenses/by/4.0/ unported [CC BY 4.0]. 


\section{Introduction}

Sexually Transmitted Infections (STIs) and Reproductive Tract Infections (RTIs) have been a major public health problem in all the developing countries. India had a National STD Control Programme even before we got our independence but did not receive due attention till the programme was merged with the National AIDS Control Programme. HIV/AIDS has now, very rightly, been recognised as an important developmental challenge with a potential to adversely affect the entire socioeconomic infrastructure of the nation [1].

The World Health Organization and The World Bank states that: "In developing countries, STDs and their complications are amongst the top five disease categories for which adults seek health care. In women of childbearing age, STDs (excluding HIV) are second only to maternal factors as causes of disease, death and healthy life lost". 340 million new cases of curable STIs occur every year globally, out of which $75-85 \%$ are there in developing countries [1].

There are many features that make India a vulnerable country for STI such as lack of a strong evidence base on which to formulate decision making, a pluralistic and often unregulated health sector and a highly vulnerable population. Vast number of people in India is severely disadvantaged in terms of income, education, power structures and gender [2].

Public health importance of STI/ RTIs lies in facts that 40 million episodes per year in India is a huge indicator of morbidity load, increased risk of getting the most serious and important STI i.e HIV and if untreated can cause serious complications, large burden of DALY loss and huge burden of treatment on economy, social impact of STI/ RTIs and HIV in the form of morbidity such as disabilities, maternal mortality leading to orphan children, socioeconomic impact of AIDS, cost to national productivity, decreased life expectancy, increased cost to health systems, adolescent and young adults psychological problems, psychosocial problems.

The steady rise in the previous years of the population in the age group of 15 - 30 years in India with changing trends in lifestyle and education sector with upcoming more liberal society has increased the number of teenagers and young adults indulging in sexual activities.
In India, these infections are no more limited to high-risk groups or in some specific geographic areas in the cities but are now prevalent all over the country.

As per NACP III action plan 40 million new episodes of curable STI/ RTIs per annum occur in India. Prevalence of suggestive symptoms of STIs/RTIs as per ICMR, 2005; multi-centric study, NIRRH, Mumbai [1] are - Women: 23 - 43\%; Men: 4 $9 \%$.As per Community-based laboratory supported STI/RTI prevalence study 2002 (ICMR-NACO), 6\% among adult population was found to be having STIs/RTIs [1]. Most important among all these is India is having 2.4 millions of living HIV infected patients (UNAIDS) [3].

Measures for preventing sexual transmission of HIV and STIs are the same, as are the target audiences for interventions. Moreover, STIs also facilitate HIV transmission. Monitoring trends in STIs provides valuable insight into the likelihood of the importance of sexual transmission of HIV within a country and the impact of behavioural interventions.

The 11 Member countries of the South East Asia Region (SEAR) endorsed WHO's "Regional Health Sector Strategy on HIV (2011-2015)" in Jaipur, India, to meet these challenges and has recognised inadequately trained health care providers and poor quality and unregulated medical services as important factors due to which STI control programmes often fail. Healthcare providers (HCPs) play an important role in reducing the burden of STI and stemming the spread of STI through effective prevention and case management.

Expanding services for screening and testing for STIs and provision of good quality STI management into primary health care, sexual and reproductive health services and HIV services have been recognised as major proposed country actions [5]. This is to ensure provision of effective treatment at first encounter. For primary care settings in lowand middle-income countries, syndromic management of STIs in patients presenting with consistently recognized signs and symptoms has been advised.

Under Syndromic management diagnosis is based on the identification of syndromes which are a combination of the symptoms the client reports and the signs the health care provider observes. The recommended treatment is effective for all the diseases that could cause the identified syndrome and provides single-dose treatment as far as possible [1]. 
Many types of barriers on both provider and client sides, untrained treatment providers and irrational use of antibiotics have further created a new problem of Drug resistant STIs. The health-seeking behaviour among the general population in India shows that for STI/RTI treatment people prefer nonmodern medicine practitioner over the modern medicine qualified practitioner. WHO Country Cooperation Strategy 2006-2011- INDIA HEALTH [6] states that India has a large and unregulated private sector which accounts for 64 percent of the beds and $3 / 4$ th expenditure of outpatient curative care services.

There are approximately 790 million users of private-sector services in India, compared to the public sector's 290 million users [7]. An estimated $80 \%$ of patients with STIs prefer to use the private sector out of which approximately $70-80 \%$ of Indians seek care from providers practicing different systems such as Ayurveda, Siddha, Unani, and Homeopathy [8].

Through our personal experience and observations during monitoring activities at designated STI centres in different districts, discussion with medical teaching faculty and reviewing available literature we are of the impression that the doctors working in different core groups (whether private or govt. sector) which generally act as the first decision maker lacks in providing adequate and quality treatment and counselling to such patients.

Many of the practising doctors seem to be totally unaware of Syndromic approach and Suraksha clinics. Similar was found by various studies in other states of India like Tamil Nadu, Karnataka and Gujarat. But, no published baseline data about knowledge and approach in the treatment of STIs of Health care providers in North India or specifically in Punjab is available with Punjab State AIDS Control Society, State Health Department, Punjab and Baba Farid University of Health Sciences, Punjab.

So, a study was conducted with intent to assess the overall awareness, current practices and approach towards care of patient's presenting with STI/ RTI symptoms among the practising private sector Primary Health Care providers. A part of it is being communicated and presented in this Paper. From the data collected through the study, efforts have been made to suggest measures to strengthen services concerning improvement in patient care and spread of STI/HIV.

\section{Aims and Objectives}

- To determine awareness and opinion regarding Syndromic approach towards STI / RTI case management among the practitioners in private sector.

- To compare the results with the previous large scale studies and to provide suitable recommendations.

\section{Methodology}

The present study was a Cross sectional study in urban Patiala. Patiala is one of the 5 major cities of Punjab, a northern region state in India. Study population was qualified health care providers in private sector. Firstly, lists of private practioners were procured and compiled after collecting information from different sources such as members list of Indian Medical Association (Patiala Chapter), private practitioners list available with Pharmacist association, online resources, information from private sector hospitals and members list of National Integrated Medical Association (Patiala Chapter). Quacks, faith healers and non degree holder practioners were excluded from the study population. Permission was granted by Institutional review and ethics committee.

The health care providers (HCPs) under the study area were categorised into two categories based on their qualification. Category 1(Group A) included allopathic practitioners employed either in private health institutions or engaged in own private practice. Doctors trained in indigenous Non allopathic medical systems such as Ayurveda and Homoeopathy were grouped in Category 2 (Group B).

Group A study population was then reduced to general MBBS practitioners and specialists of Medicine, General Surgery, Dermatology and Gynaecology only to make the target population more specific. The other private practioners practising super speciality services and specialists of other streams were excluded.

Sample size calculated keeping allowable error at $10 \%$ was found to be 89 . It was extended and round figured to 100 . Since, no. of practioners in both the selected groups was almost equal so50 each from both the categories were selected. Though NACO guidelines for STI case management were more relevant to Category 1 but Category 2 was included in the study, because of the fact that a 
Major portion of patients access care for STIs from these HCPs.

A pre-structured, pretested questionnaire was developed. The questionnaire contained mainly closed and a few open-ended questions. Randomly selected Health care practioners in both groups were personally visited from September 2012 to August 2013. He/ She were ensured that the confidentiality will be maintained and this study is not to assess their individual knowledge. The selected practioner if found unwilling to participate was left and next randomly selected practioner was then visited till 50 respondents were covered in both the groups.

The Practioners who participated in both the groups have been marked and plotted on Google map of Patiala city as shown in Figure 1 (Group A) and Figure 2 (Group B).As per the objectives, data was compiled and analysed using MS Excel and requisite suitable scientifically valid information was extracted.

\section{Results and Observations}

Table 1 shows distribution of the studied participants based on their qualification and experience. In Group A; $32 \%$ participants were having qualification of MBBS, rest $68 \%$ were having specialization; of which $20 \%$ were Gynaecologist, $20 \%$ were Surgeon, $18 \%$ were Physician (MD medicine) and $10 \%$ were Dermatologist. In Group B, $60 \%$ were having BAMS qualification, $14 \%$ were having Post graduate degrees after BAMS, $12 \%$ were BHMS, $12 \%$ were DHMS and $2 \%$ were having post graduate diploma after BAMS.

Table1 also depicts that participants in Group A had a mean years in practice after graduation of 16.32 years with a range of 1 - 40 years and median of 14 years while Group B had a mean years in practice after graduation of 16.26 years with a range of 2 52 years and median of 14.5 years. This shows that both the groups are similar in experience and hence are comparable. It was an advantage that the two groups were comparable on the basis of experience.

In response to question asking conditions/signs/symptoms countered in the patients presented to them in their service/practice, the responses gathered have been presented in Table 2. It depicts that practitioners in both the groups counter the patients presenting with symptoms suggestive of STI/ RTI.
Most common condition countered by both the groups was lower abdominal pain and less common were inguinal bubo, genital warts in both the groups. Major difference was seen in cases of HIV, Hep B \& C countered during practice where only 28 $\%$ non allopathic practitioners had observed any known case of HIV in comparison to $54 \%$ of allopathic practitioners. Among Group B, 50\% and $20 \%$ have countered $\mathrm{HBs} \mathrm{Ag}+(\mathrm{Hep}-\mathrm{B})$ and $\mathrm{HCV}$ +ve (Hep-C) cases respectively in comparison to 78 $\%$ and $54 \%$ respectively in Group A.

Only $14 \%$ among Group A and only $2 \%$ among Group B in the present study had ever undergone any training on STI/ RTI. It clearly shows lack of training among private practioners. When the participants were asked about their willingness to undergo short training/ CME/Seminar on STI/RTI/ HIV, $58 \%$ of the participants in Group A were willing to attend while in Group B $74 \%$ had shown interest. It indicates higher interest to gain knowledge among non-allopathic private practioners.

Table 1:Qualification and experience of the Participants

\begin{tabular}{|l|l|}
\hline GROUP A - Allopathic $(n=50)$ & GROUP B - Non-allopathic $(n=50)$ \\
\hline
\end{tabular}

\begin{tabular}{|l|l|l|l|}
\hline Qualification & Number & Qualification & Number \\
\hline MBBS & $16(32 \%)$ & BAMS & $30(60 \%)$ \\
\hline MD Gynae & $10(20 \%)$ & BAMS + MD & $07(14 \%)$ \\
\hline MS Surgery & $10(20 \%)$ & BHMS & $06(12 \%)$ \\
\hline MD Medicine & $09(18 \%)$ & DHMS & $06(12 \%)$ \\
\hline MD Skin & $05(10 \%)$ & BAMS + PG Diploma & $01(02 \%)$ \\
\hline TOTAL & 50 & TOTAL & 50 \\
\hline Years in Practice after Graduation & \multicolumn{2}{|l}{} \\
\hline Mean & 16.32 yrs & Mean & $16.26 \mathrm{yrs}$ \\
\hline Median & 14 yrs & Median & $14.5 \mathrm{yrs}$ \\
\hline Range & $1-40$ yrs & Range & $2-52 \mathrm{yrs}$ \\
\hline
\end{tabular}

Table 2: Conditions/ signs/ symptoms countered in patients in OPD

\begin{tabular}{|l|l|l|}
\hline \multicolumn{1}{|c|}{ Conditions/signs/symptoms } & Group A ( $\mathbf{n}=50)$ & Group B (n= 50) \\
\hline a) Genital Ulcers & $26(52 \%)$ & $35(70 \%)$ \\
\hline b) Urethral / Vaginal Discharge & $43(86 \%)$ & $33(66 \%)$ \\
\hline c) Lower abdominal pain & $45(90 \%)$ & $47(94 \%)$ \\
\hline d) Inguinal bubo's & $10(20 \%)$ & $12(24 \%)$ \\
\hline e) Dysuria & $41(82 \%)$ & $40(80 \%)$ \\
\hline f) Burning sensation in genital region & $36(72 \%)$ & $30(60 \%)$ \\
\hline g) Genital warts/cutaneous growth & $17(34 \%)$ & $12(24 \%)$ \\
\hline h) Anorectal discharge & $12(24 \%)$ & $19(38 \%)$ \\
\hline i) Genital scabies/ itching & $24(48 \%)$ & $24(48 \%)$ \\
\hline j) Known case of HIV & $27(54 \%)$ & $14(28 \%)$ \\
\hline k) H/o unprotected sexual contact & $25(50 \%)$ & $18(36 \%)$ \\
\hline
\end{tabular}




\begin{tabular}{|l|l|l|}
\hline 1) Suspicion of getting STI & $28(56 \%)$ & $17(34 \%)$ \\
\hline m) $\mathrm{HBs} \mathrm{Ag}+$ & $39(78 \%)$ & $25(50 \%)$ \\
\hline n) $\mathrm{HCV}+\mathrm{ve}$ & $27(54 \%)$ & $10(20 \%)$ \\
\hline
\end{tabular}

Table 3: Awareness of the "Syndromic approach"

\begin{tabular}{|c|c|c|}
\hline & Group $A(n=50)$ & Group B $(n=50)$ \\
\hline Yes & $30(60 \%)$ & $19(38 \%)$ \\
\hline No & $20(40 \%)$ & $31(62 \%)$ \\
\hline \multicolumn{3}{|c|}{ I If YES, how many types of kits are being provided? } \\
\hline & Group $A(n=30)$ & Group B $(n=19)$ \\
\hline Correct reply ( 7 Kits) & $16(53.33 \%)$ & $4(21.05 \%)$ \\
\hline \multicolumn{3}{|c|}{ Awareness regarding "Suraksha Clinic" } \\
\hline & Group A $(n=50)$ & Group B $(n=50)$ \\
\hline Yes & $7(14 \%)$ & $5(10 \%)$ \\
\hline No & $43(86 \%)$ & $45(90 \%)$ \\
\hline \multicolumn{3}{|c|}{ If YES, can you tell the location of nearest "Suraksha Clinic" } \\
\hline & Group A $(n=7)$ & Group B $(n=5)$ \\
\hline Could reply & 3 & 1 \\
\hline
\end{tabular}

\section{Table 4: Opinion on Syndromic case} management

\begin{tabular}{|l|l|l|}
\hline \multicolumn{1}{|c|}{ Options } & \multicolumn{1}{|c|}{$\begin{array}{c}\text { Group } \\
\mathbf{A}(\mathbf{n = 5 0 )}\end{array}$} & \multicolumn{1}{|c|}{$\begin{array}{c}\text { Group } \\
\mathbf{B}(\mathbf{n = 5 0 )}\end{array}$} \\
\hline a) Generates Better follow up & $36(72 \%)$ & $33(66 \%)$ \\
\hline b) Risk of over treatment & $20(40 \%)$ & $17(34 \%)$ \\
\hline c) Ideal for current infra structure & $27(54 \%)$ & $20(40 \%)$ \\
\hline $\begin{array}{l}\text { d) No medical/scientific basis for this } \\
\text { approach. }\end{array}$ & $6(12 \%)$ & $4(8 \%)$ \\
\hline e) Should be only used. & $6(12 \%)$ & $12(24 \%)$ \\
\hline f) Should not be used & $2(4 \%)$ & $3(6 \%)$ \\
\hline
\end{tabular}

Table 5: Treatment modality being used

\begin{tabular}{|l|l|l|}
\hline \multicolumn{1}{|c|}{ Options } & \multicolumn{1}{|c|}{$\begin{array}{c}\text { Group A -Allopathic } \\
(\mathbf{n = 5 0})\end{array}$} & \multicolumn{1}{|c|}{$\begin{array}{c}\text { Group B- Non-allopathic } \\
(\mathbf{n = 5 0})\end{array}$} \\
\hline $\begin{array}{l}\text { a) Allopathic drugs } \\
\text { bits NACO advised }\end{array}$ & 29(98\%) & $37(74 \%)$ \\
\hline $\begin{array}{l}\text { c) Ayurvedic } \\
\text { medicines }\end{array}$ & 0 & $1(2 \%)$ \\
\hline $\begin{array}{l}\text { d) Homeopathic } \\
\text { medicines }\end{array}$ & 0 & $30(60 \%)$ \\
\hline e) Any other & 0 & $14(28 \%)$ \\
\hline
\end{tabular}

In reply to question asking directly about their awareness about Syndromic approach $60 \%$ in Group A and 38 \% in Group B admit to be aware of Syndromic approach but only 16 in Group $A$ and 4 in Group B had correctly replied about no. of kits available in syndromic approach (Table 3).Awareness regarding Suraksha Clinic was found to be much low, only $14 \%$ and $10 \%$ participants in Group A and B respectively had ever heard about Suraksha Clinic.
Those who were not aware of syndromic approach were briefly told about it, in predefined terms that "It is the approach being advised by International and National agencies to go for treatment regimens available as kits based on the identification of consistent groups of symptoms and easily recognized signs (syndromes), which will deal with the majority or most serious organisms responsible for producing a syndrome complimented by appropriate laboratory investigations where facilities exist." Then their opinion regarding this approach was asked, findings are being presented in Table 4.

Regarding treatment modality being used by the practioners in management of STI/ RTIs, 98\% among Group A which comprises Allopathic practioners uses allopathic drugs while $2(4 \%)$ of them told about using NACO advised kits at any moment during their practice (Table 5). The participants in Group B, although comprising of Non allopathic practioners but $74 \%$ admit prescribing allopathic medicines in such patients along with Ayurvedic and Homeopathic medicines which is worth consideration.

\section{Discussion}

Since, it has been shown by the previous studies that majority of patients in Punjab [9], we can also say in India [10] prefer consulting private practioners and more often non allopathic. So, it becomes important by itself that quality of STI management practices must be ensured by involving private practioners.

A study in a nearby city Ludhiana concludes that the most common symptoms reported by the women sufferers were urinary (dysuria $57.8 \%$, frequent urination $53.3 \%$ ), followed by dyspareunia $(26.7 \%)$, unusual vaginal discharge $(24.4 \%)$ and vaginal itching (22.2\%). $64.4 \%$ of those with symptoms were untreated, $68.7 \%$ of those treated reported partial relief, most of those treated preferred private doctors, and the partners were not treated [12].

Similarly in Karnataka among the interviewed medical practitioners two-thirds reportedly received STI patients and one-half received HIV/AIDS patients. Almost all these practitioners treat STI patients but only $1 / 3$ rd treat HIV/AIDS patients. Most common symptoms observed in male STI patients were genital sores/ulcers, genital discharge/dripping and burning pain on urination followed by genital itching, redness/ inflammation in genital area, and groin swelling. 
In female STI patient's vaginal/foul smelling discharge was the commonest followed by lower abdominal pain, burning pain on urination and genital sores/ulcers [13].

Regarding training similar trends were observed in Karnataka where $40 \%$ of all medical practitioners and $60 \%$ of those who receive at least five STI and HIV/AIDS patients have received training in STI and HIV/AIDS14.46\% of allopaths, $51 \%$ of qualified non -allopaths and $67 \%$ of RMPs were interested to undergo such training and are also willing to pay for it [8] and in Gujarat HCPs had indicated during the in-depth interviews that there was a dire need to improve the attitudes and skills of most of the HCPs and other related staff members for imparting the recommended STI case management [14].

In Karachi, Pakistan also $92 \%$ of the doctors were interested in attending continuing medical education seminars on STI control, and $95 \%$ were willing to follow a standardized protocol for the management and counselling of STI patients [15].

While in Karnataka, $55 \%$ of the practitioners who treat STI patients were aware of syndromic case management and of them more than $80 \%$ claimed to have followed syndromic case management for STI treatment [13]. In present study around $70 \%$ in both the groups were of the opinion that it will generate better follow up while 35-40 \% believe there is a risk of over treatment with this approach.

In Gujarat 38.5\% allopathic practitioners had said that syndromic case management had a better follow up. More than 1/4thof allopathic HCPs expressed that risk of over treatment was one of the limitations of SCM [14]. In Karnataka, 45 \%responded that it is more scientific and adequately treats mixed infections and 25-30\% states that it is cost-effective and requires single visit only even if the patient had multiple infections [13].

The present study thus concludes that private practioners of both allopathic and non allopathic (indigenous system of medicine, AYUSH) streams in the study area are managing the STI / RTI patients in sufficiently large numbers. Proportion of practioners who had ever undergone training on STI/RTI is meagre and negligible depicting lagging status of Punjab.

It indicates the requirement of some mechanism for regular formal or informal educational activities for licensed practioners in the form of short trainings,
CME, seminars or printed educational material and treatment guidelines. This becomes more important when these private practioners especially Non allopathic practioners themselves recognise need for such trainings and are willing to undergo trainings on STI/RTI management.

As many of the practioners are not aware of Suraksha Clinics, how can one hope that these practioners will refer such patients to such designated centres for HIV testing, ICTC for counselling. This further lends its effect on missed out cases of HIV.

Since, practice of syndromic case management of STIs is presumed to be dependent on the HCP's individual opinion and attitude towards syndromic case management hence it is beneficial to know about their opinion.

To raise the rates of treatment and prescriptions as per WHO advised strategy of Syndromic management, confidence building and appropriate knowledge to the health care providers is a must. Only then we can hope that the adopted strategy can be turned into practice if negative perceptions among practioners would be handled carefully.

It is of serious concern that almost 3/4th of Non allopathic practioners are using allopathic medicines in such cases along with Ayurvedic/ Homeopathic medication. Neither they are qualified for it nor are they adopting 'Syndromic approach'. Such practices will likely result in drug resistant cases.

\section{Conclusions}

The present study was one of the first of its kind done in north India. Although similar studies have been conducted in other states such as Gujarat and Karnataka but no baseline data was available for this region.

Since, adequate management with appropriate medication is the right of every citizen and it is the responsibility of the administration to provide so and moreover the need for training and supervision has been felt at every aspect in this study whether in terms of refreshing their knowledge, developing attitudes or monitoring the practices of managing the STI/ RTI patients.

It is expected that these results will also be useful for agencies and individuals involved inthe fight against STI/HIV/AIDS elsewhere in the country. 


\section{Recommendations}

- Measures should be taken to spread information regarding National guidelines and services available to the private practitioners through State AIDS Control Societies (SACS) and District AIDS Prevention and Control Units (DAPCU). Since, Practice of syndromic case management of STIs is presumed to be dependent on the HCP's individual opinion and attitude towards syndromic case management, it becomes essential to educate the licensed private practitioners by short trainings, $\mathrm{CME}$, seminars or printed educational material and ideal treatment protocols as per the national guidelines and motivate them to adopt practice of Syndromic case management or refer such cases to nearest Suraksha Clinics.

- Harmful practices of unregulated usage of allopathic medicines(antibiotics) by AYUSH group of practioners neither with adequate training nor using Syndromic approach, leads to irrational medication and development of resistance and should be stopped or otherwise AYUSH practioners be adequately trained.

- Hands on trainings can be planned after deriving some policy for inclusion of non-allopathic practioners regarding management of STI/RTI, these should be monitored by State Medical Councils.

\section{Reference}

01. Resource material for training of doctors to deliver quality STI/ RTI treatment. National AIDS Control Organization. Ministry of Health \& Family Welfare, Government of India. Oct 2008. [Crossref]

02. Hawkes S, Santhya KG. Diverse realitiessexually transmitted infections and HIV in India. Sex Transm Infect. 2002 Apr;78 Suppl-1;i31-9. [Crossref]

03. AIDS in India. History and statistics. Internet source.

Available at: [Article] [Crossref]

04. National AIDS Control Program Phase III (20062011). Strategy and Implementation Plan; National AIDS Control Organization. Ministry of Health \& Family Welfare, Government of India. Nov $30 ; 2006 ; 13$.

[Crossref]
05. Regional health sector strategy on HIV, 20112015. WHO - SEARO.

Available at: [Article] [Crossref]

06. WHO Report. WHO Country Cooperation Strategy. India health development. 2007 Aug. Available online [Article] [Crossref]

07. USAID (2008) Country Health Statistical ReportIndia. Available at: [Article] [Crossref]

08. McCarthy E, Beals J, Haffey J, Lugo LR, Harvey SA. India STI case study- Diagnostic Services for Sexually Transmitted Infections in Three Indian States. Bethesda, MD- Center for Human Services. 2010.

Available online : [Article] [Crossref]

09. Bhavsar R D, Singh J P, Khanna A. Determinants of STIs/RTIs among women in Punjab and their health seeking behaviour. Indian Institute of Health Management Research. 1998-99.

[Crossref]

10. Mignone J, Washington RG, Ramesh BM, et al. Formal and informal sector health providers in southern India- role in the prevention and care of sexually transmitted infections, including HIV/AIDS. AIDS Care. 2007 Feb;19(2)152-8.

[Crossref]

11. Mertens TE, Smith GD, Kantharaj K, Mugrditchian D, Radhakrishnan KM. 1998, Observations of sexually transmitted disease consultations in India. World Health Organisation, Public Health. 1998 Mar;112(2)123-8.

[Crossref]

12. Philip PS, Benjamin AI, Sengupta P. Prevalence of symptoms suggestive of reproductive tract infections/sexually transmitted infections in women in an urban area of Ludhiana. Indian J Sex Transm Dis. 2013 Jul;34(2)83-8. doi: 10.4103/0253-7184.120537 [Crossref]

13. Rajaretnam T, et al. Baseline Survey report, assessment of practice of STI and HIV/AIDS Care by medical practioners in Karnataka. Population Research Centre, JSS Institute of Economic Research; Vidyagiri, Dharwad. Oct, 2004.

[Crossref] 
14. SUMMARY REPORT: Health Care Provider Survey in Gujarat, India. Gujarat state AIDS control society, part of a series of baseline surveys conducted to monitor the impact of HIV/STI prevention programmes in five states of IndiaAndhra Pradesh, Gujarat, Kerala, Orissa, West Bengal and in the Healthy Highways Project. 2001.

[Crossref]
15. Khandwalla HE, Luby S, Rahman S. Knowledge, attitudes, and practices regarding sexually transmitted infections among general practitioners and medical specialists in Karachi, Pakistan. Sex Transm Infect. 2000 Oct;76(5)383-5.

[Crossref] 